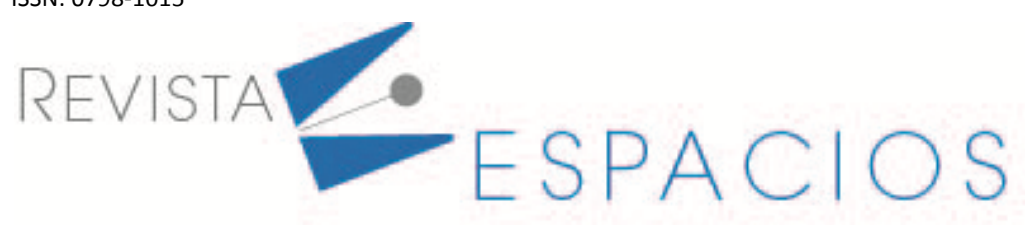

\title{
Teorias e abordagens investigativas em didática, formação de professor e integração das TDIC ao currículo
}

\section{Theories and investigative approaches in teaching, teacher training and integration of TDIC to the curriculum}

\author{
SILVANO, Antonio Marcos da C. ${ }^{1}$ \\ MELO, Cleilton B. ${ }^{2}$ \\ JUNIOR, Antonio Sinval B. ${ }^{3}$ \\ MATOS, Efraim A. ${ }^{4}$
}

\begin{abstract}
Resumo
O presente trabalho se propõe a realizar um estudo exploratório sobre o processo formativo de professores a partir do uso das TDIC sob a concepção da análise do impacto da relação que se establece entre a Didática e o uso das tecnologias de forma integrada. Tal estudo aponta para uma relação mediada pelos professores utilizando as TDIC como ferramenta potencializadora das aprendizagens. Ainda há um vasto campo a se explorar, mas já apresentamos aquí um subsídio teórico inicial.

Palavras-chave: TDIC. formação docente. didática.
\end{abstract}

\begin{abstract}
This work proposes to carry out an exploratory study on the teacher training process from the use of TDIC under the conception of the analysis of the impact of the relationship established between Didactics and the use of Technology in an integrated manner. This study points to a relationship mediated by teachers using TDIC as a tool to enhance learning. There is still a vast field to be explored, but here we present an initial theoretical subsidy.

Keywords: TDIC. teacher training. didactics.
\end{abstract}

\section{Introdução}

No atual contexto educacional brasileiro, constatamos uma expressiva produção de trabalhos científicos realizados por pesquisadores e estudiosos da área de ensino na perspectiva de ampliarem os horizontes em relação aos temas da didática, compondo os processos formativos do docente aliados à integração das Tecnologias Digitais da Informação e Comunicação (TDIC) ao currículo, aqui visto como um conjunto de práticas de ensino ancoradas e estruturadas a partir de objetivos pedagógicos. Tais investigações traçam passos na busca por novas alternativas para o cenário da educação brasileira concernente à formação didática e epistemológica dos docentes, de modo atender às necessidades da sociedade contemporânea.

\footnotetext{
${ }^{1}$ Professor e Coordenador do Curso de Licenciatura em Matemática. IFCE Campus Cedro. marcos.silvano@ifce.edu.br

2 Professor do Curso de Licenciatura em Matemática. IFCE Campus Cedro. cleilton.melo@ifce.edu.br

${ }^{3}$ Professor do Curso de Licenciatura em Matemática. IFCE Campus Cedro. antonio.junior@ifce.edu.br

${ }^{4}$ Professor do Curso de Licenciatura em Matemática. IFCE Campus Cedro. efraim.matos@ifce.edu.br
} 
Nesse sentido, é necessário renovar e promover saberes docentes ligados à formação inicial ou continuada, mas sobretudo na graduação, de maneira que estes possam refletir acerca de suas funções na busca de estratégias metodológicas necessárias ao enfrentamento e superação dos desafios vão se delineando nas realidades escolares, especialmente no que tange ao domínio, utilização pedagógica das TDIC.

A construção e execução de atividades interativas e colaborativas envolvendo ferramentas tecnológicas como computador, smartphones, tablets, e consequentemente a internet, como base para a prática pedagógica pode se apresentar como elemento essencial para o desenvolvimento de construção de saberes docentes em sua primeira etapa formativa. Permitindo reflexões e elaborações desses saberes, metodologias e estratégias significativas ao fazer docente, tais atividades agregam fatores como incentivo, sendo capazes de ampliar as potencialidades de aprendizagem. Valorizando, assim, a elaboração de percursos formativos de modo a estabelecer uma perspectiva interdisciplinar ao currículo, além de elos entre o que se estuda e o mundo em que se está inserido, podendo propor soluções a situações que surjam (Almeida; Valente, 2011; Ribeiro et al., 2008).

A partir disso, deve-se ter claro que a inclusão de tecnologias digitais em ambientes escolares não seja apenas de acesso e de uso restrito dessas tecnologias digitais (práticas difusionistas), mas que possilite a articulação das tecnologias ao trabalho pedagógico do professor numa dimensão cognitiva. Dessa forma, a partir de uma base epistemológica que visa essa inserção como meio para auxiliar os processos de ensino e de aprendizagem dos saberes pedagógicos, disciplinares, didáticos, e digitais e de pesquisa, não numa relação de causa e efeito, mas numa perspectiva holística Okada, (2013); Bprges Neto; Junqueira, (2009); Ribeiro, (2012); Young( 2014).

Por construção de saberes docentes, entendemos que isso consiste em um processo complexo que tem interrelações produtivas e produtoras da subjetividade do professor, considerando suas experiências de vida, sua composição identitária e seus conhecimentos profissionais, possibilitando o desenvolvimento de novas relações cognitivas, a partir de um saber-fazer, de uma relação dialética entre teoria e prática, as quais são efetivamente mobilizados e utilizados para a atividade docente (Therrien ,( 2006); Pimheiro ( 2016).

Estes saberes docentes estão relacionados a uma conjunto de procedimentos e atitudinais envolvendo o professor, tanto no aspecto pessoal, quanto no social, culminando no aspecto profissional (THERRIEN, 2006; PINHEIRO, 2016). Para Tardif (2008, p. 11), “o saber dos professores está relacionado com a pessoa, sua identidade, experiência de vida, história profissional, relações com alunos em sala e com os demais atores envolvidos no contexto escolar". Trata-se do saber do professor adquirido em sua práxis e, primeiramente, em sua formação inicial.

Esse fato nos remete a uma reflexão crítica no que tange ao uso e apropriação das TDIC no ensino e no desenvolvimento constitutivo de saberes Borges Neto; Junqueira, (2009) na primeira etapa formativa do professor frente às necessidades e demandas emergentes da atual sociedade, inclusive no contexto escolar, no qual a forma como se compreende a realidade em que estamos inseridos é preponderante para domínio de habilidades, bem como estabelecimento de metodologias que permitam o mapeamento de informações, arquivos, tecnologías e redes colaborativas, visando uma maior qualidade ao ato de aprender e ensinar(Almeida; Valente,( 2011); Okada, (2008c); RIBEIRO et al., (2008).

Nosso interesse não é esgotar as discussões e análises sobre esse campo de estudo, mas facilitar a compreensão no que tange ao processo de formação docente quanto aos saberes e conhecimentos, além de sua articulação. Esse diálogo se establece a partir da integração à prática pedagógica das potencialidades das TDICs sob uma perspectiva não essencialmente estruturalista, possibilitando melhores desempenhos acadêmicos ao ato de ensinar que se configura junto ao de aprender.

Para tais discussões, é salutar enfatizar que utilizamos os pressupostos e contribuições dos trabalhos de Tardif (2008), Pimenta (2011), Freire (1997) e Gauthier (2014) para corroborar com a construção do quadro teórico- 
metodológico embasado em uma epistemologia da práxis, na dialogicidade e racionalidade que move a ação docente e nas contribuições das pesquisas de Almeida, Valente (2011) e Almeida (2012) sobre a integração das TDIC ao currículo, logo aos fazeres docentes, uma vez que o primeiro é a estratégias que se estabelece para chegar a uma efetiva prática do segundo.

As pesquisas acadêmicas em educação têm contribuído significativamente no sentido de ampliar o que se entende acerca dos saberes docente (específico da área de atuação, curriculares, pedagógicos e experienciais). Além disso, tem contribuido para o entendimento das concepções epistemológicas do uso dos recursos e das próprias TDIC. Ao estabelecer integração ao currículo contribui para uma aprendizagem mais completa, respeitando a complexidade e efetivando o que se propõe dentro de processos didáticos ao se trabalhar os conteúdos na relação que se estabelece entre docentes e discentes.

Para Imbernón (2011), os investimentos que são feitos em cursos de formação docente apontam para caminhos de melhoria dos processos educativos do país, promovendo uma construção e/ou renovação de suas concepções no que tange à postura do professor diante do fazer pedagógico na escola. Torna-se imperativo que os contextos experienciados por esses profissionais passem por modificações, contudo, o professor precisa perceber a existência de uma relação estreita entre as concepções que possuem e as ações pedagógicas que desenvolvem. Essa percepção pode acontecer de forma inconsciente, visto que essas concepções direcionam tanto a postura como o modo de ensinar do docente nos espaços escolares formais.

Há pesquisas que buscam conceber novas abordagens interdisciplinares em diversos campos da educação com um maior enfoque nos aspectos ontológico, epistemológico e metodológico considerados pilares da formação docente seja da educação básica ou superior. Seguem contribuido satisfatoriamente para compreensão dos pressupostos teóricos e práticos que subsidiam as diversas esferas da ação docente construindo saberes emergentes ao mobilizar e articular conhecimentos Therrien (2006).

Diante do exposto, o objetivo deste trabalho é propor um estudo exploratório sobre o processo formativo de professores a partir do uso das TDIC sob a concepção da análise do impacto da relação que se establece entre a Didática e o uso da Tecnologia de forma integrada. Aqui a ação docente é vista como como elemento central para o desenvolvimento do ensino, caminhando para uma aprendizagem mais significativa. Nesse sentido, justifica-se pela imprescindibilidade de construir novas compreensões sobre a utilização das TDIC no processo de formação docente dentro de realidades pedagógicas, bem como a integração desses recursos à prática pedagógica.

\section{A Didática e a formação docente}

A educação, compreendida dentro dos espaços escolares, é dividida em distintos níveis além de modalidades. Nesse sentido, temos a didática como elemento inicial ao se pensar a formação de profesores. Juntas, a prática docente e a didática, configuram assuntos bastante explorados em pesquisas, sejam elas qualitativas ou quantitativas, revelando um cenário que configura como prioridade entre os temas pesquisados, devido à relevância que ocupam nos processos de ensino e de aprendizagem.

É interesante percebermos que "A necessidade de uma reflexão sobre as tendências investigativas no campo da Didática vem tomando forma nos debates e reflexões sobre formação de professores a partir da própria realidade em que estamos inseridos Lima, p.1, (2014)", apontando para uma necessidade de contextos formativos que priorizem a realidade na qual discutimos, construímos e refletimos sobre as ações do outro permeadas nesse conjunto de relações que exercemos no espaço escolar. 
Verificamos que é necessário a inclusão das tendências investigativas da didática nos debates e reflexões sobre formação docente a partir da realidade que estamos inseridos, pois, desse contexto, podemos estabelecer quais as concepções prioritárias para o aperfeiçoamento e qualificação do docente no que tange à educação, superando a ideia de quem sabe o conteúdo, sabe ensinar.

A didática retoma ao "saber fazer" ou "como fazer" e, portanto, é inegável a necessidade do domínio de uma competência técnica que tenha conexões com a proposta pedagógica dos cursos de formação (inicial e continuada) delineando-se de tal forma que possa alcançar as necesidades que emergem dentro dos contextos escolares, a partir do fazer docente e suas implicações na formação do sujeito discente. Sendo isso possível graças, também, à efetiva integração das TDIC ao currículo e prática pedagógica docente.

Para Lima (2014), saber ensinar é uma competência técnica reflexiva que demanda estudo, pesquisa, conhecimentos e saberes da práxis docente, partindo da posse dos saberes da didática, dos saberes pedagógicos e de uma reflexividade da prática sobre a prática por meio de contextos de formação que se retroalimentam, promovendo e sendo promovidos a partir de diálogos formativos, do aperfeiçoamento e qualificação do fazer docente.

Compreendemos, ainda, que pesquisar sobre ensino e didática na atividade docente seja um importante campo de investigação a ser empreendido. Assim, legitimam-se os diversos percursos metodológicos traçados em pesquisas e suas respectivas análises, como objeto dos fenômenos inerentes à formação de professores nos diversos contextos em que os cursos de formação de professores fazem parte. Entretanto, pensamos ser importante enfatizar a imprescindibilidade de socialização das várias experiências de pesquisas sobre a fomra como se moviliza e articula saberes num caminho de desenvolvimento do conhecimento pedagógico e saberes docentes. Nessa perspectiva sobre a didática entendemos que,

A Didática opera a interligação entre teoria e prática. Ela engloba um conjunto de conhecimentos que entrelaçam contribuições de diferentes esferas científicas (teoria da educação, teoria do conhecimento, Psicologia, Sociologia, etc.), junto com requisitos de operacionalização. Isto justifica um campo de estudo com identidade própria e diretrizes normativas de ação docente, que nenhuma outra disciplina do currículo de formação de professores cobre ou substitui. Essa é a razão pela qual é tomada como 'disciplina integradora (LibÂneo, 2011, p.134).

Ainda num diálogo com o autor supracitado, percebemos que a didática assume um papel de suma importância na formação docente, tendo a função integradora entre a teoria e a forma como o docente executa sua prática. Essa dualidade forma, assim, os pilares da prática docente, e que, com certeza, vai acompanhar o professor por toda a sua vida, permeando as suas práticas na escola.

Os pressupostos epistemológicos do ensinar e do aprender são categorias norteadoras do trabalho docente frente aos desafios da atualidade e da complexidade da atividade pedagógica inserida no contexto da sala de aula, bucando algo que contemple os princípios metodológicos concebidos epistemologicamente numa prática que traduza a intencionalidade e o caráter construtivo e reflexivo do trabalho docente.

Portanto, a construção da identidade docente, organizada em diversas variantes, se dá de forma reflexiva no que comprende a didática. Só assim esse profissional poderá conceber uma prática pedagógica emancipadora, capaz de conduzir ao desenvolvimento de competências cognitivas da práxis docente nos permite alcançar melhores desempenhos profissionais tanto de quem ensina quanto daquele que aprende, sendo um ciclo de ação do fazer pedagógico.

Mobilizar saberes da didática é uma prática fundamental para o desdobramento da ação pedagógica do docente quando pautamos um ensino que priorize a reflexão e a criatividade do ser humano que aprende. Aprimorar as 
capacidades teórico-metodológicas de ensino é algo que se constrói no percurso da atividade docente, que se constitui desde a sua formação inicial, até o exercício da ação que pode acontecer por meio da implementação de estratégias gerais e especificas de ensino durante a mediação pedagógica dos conteúdos escolares.

Segundo Gauthier, Bissonnette e Richard (2014) é importante que o professor destine certa atenção ao uso de estratégias gerais e específicas de ensino durante a fase de interação com alunos, possibilitando maior interação dos discentes no desenvolvimento de novos saberes de forma significativa e contextualizada numa perspectiva de ensino explícito. Dentre as estratégias gerais, o autor destaca: maximizar o tempo de aprendizado escolar, garantir taxa de sucesso elevada dos alunos, cobrir a matéria a ser ensina, favorecer atividades em grupos, dar apoio à aprendizagem dialogada bem como utilizar uma linguagem clara, compreensiva e adequada aos contextos locais de discentes.

Gauthier, Bissonnette e Richard (2014) definem fase de interação como o instante da aula propriamente dita e, que nesse espaço se dá o estabelecimento de artifícios que promovam a dialogicidade que o docente utiliza com os alunos para garantir um aprendizado dos conteúdos, habilidades e regras preconizadas no programa. Ainda com ese autor temos o que denominaremos de efeito professor como sendo a capacidade empreendida pelo professor para desempenhar com sucesso o trabalho docente, atingindo os objetivos e finalidades do plano pedagógico de ensino explícito.

Nesse sentido, confrontando a temática da Didática e da formação docente, temos possibilitada uma visão ampliada, e concomitantemente específica, sobre o processo formativo de futuros professores, principalmente aqueles que se propõem a ser docentes da área da matemática e que concepções acerca do ato de ensinar e de aprender, bem como da didática construíram nesse ínterim formativo.

Os cursos de licenciatura em matemática, em grande parte, privilegiam os saberes específicos do campo de matemática dedicando maiores cargas horárias às disciplinas como cálculo, álgebra, análise matemática entre outras, ficando muitas vezes lacunas na formação didático pedagógica desses futuros professores. Esses cursos de formação docente se assemelham aos cursos de bacharelado, onde o principal objetivo é conhecer os conteúdos específicos de matemática, no qual não há uma olhar mais atento a questões ligadas à didática, aos saberes pedagógicos e curriculares apresentando limitações na trabalho desse futuro professor.

De modo preliminar, as reflexões, embasadas nas concepções teóricas das pesquisas que discutem a didática e a formação de profesores, têm contribuído fortemente para o desenvolvimento de uma rede complexa de questões como: saberes pedagógicos e curriculares, racionalidade e dialogicidade da práxis docente, relações intersubjetiva dos atores do espaço escolar formal.

Pimenta (2011) assinala que muitos cursos de formação inicial de professores no Brasil dão prioridade em seu currículo para as disciplinas específicas da atuação dos professores, ficando em segundo plano as disciplinas que discutem os conhecimentos e saberes pedagógicos e didáticos, refletindo negativamente na construção e ação do professor quando é tempo de interação e diálogos para formação de saberes referentes aos conteúdos.

Essas lacunas e fragilidades relacionadas aos aspectos ligados à didática em relação a formação docente têm consequências negativas no contexto e na prática de ensinar, pois tal profissional necessita de um entendimento mais reflexivo sobre como os alunos aprendem e só assim ele poderá ensinar dentro de uma perspectiva crítica e permeada de significados, valorizando seus conhecimentos prévios, a cultura e as realidades sociais do entorno escolar.

Os docentes que passam por essa formação colocam em evidências o despreparo no que tange ao ato e as bases para planejar, as metodologias e avaliação do seu fazer e de seus objetivos de ensino, caracterizando uma 
formação limitada quando pensamos em quais saberes devem estar assentada, bem como de saberes docentes fundamentais para a condução do trabalho frente às demandas que vão se delineando no que tangencia a escola.

Para Tardif (2008):

O saber docente não é um objeto ou coisa que flutua no espaço; o saber dos professores é o saber deles e está relacionado com a pessoa e a identidade deles, com a sua experiência de vida e com a sua história profissional, com as suas relações com os alunos em sala de aula e com os outros atores escolares na escola (TARDIF, 2008, p.11).

O profesor, qualificado técnica e pedagogicamente para atuar na atividade docente pautada nas discussões e formação crítica de seus discentes, necessita de uma construção profissional ética concreta concebida a partir de suas vivências, história de vida, de seus valores e princípios para desempenhar o oficio de ensinar e de construir uma aprendizagem significativa dos alunos.

\section{Repensando o fazer docente e o currículo a partir das TDIC}

A sociedade tem se desenvolvido nos últimos anos imersa em tecnologias, aqui pontuando as digitais, com especial uso para as interfaces digitais interativas que permitem a comunicação e a informação como os computadores, smartphones, tablets, entre outros. Dessa forma, é necessário que, para a construção de seus conhecimentos, alunos e professores estejam articulando saberes e conhecimentos digitais ao utilizar essas ferramentas e, nesse sentido, o contexto escolar precisa criar pontes entre pessoas e as TDIC. Não podendo assumir uma postura de que essas ferramentas sejam utilizados somentes fora dos muros desses locais, pois o exercício docente pode ser potencializado se esses profissionais são continuamente formados para utilizar pedagógica e cognitivamente em diversos contextos tais ferramentas (Valente, 2003).

Com o desenvolvimento nos últimos anos de ferramentas tecnológicas avançadas Os anos foram passando e as realidades da educação evoluíram consideravelmente rápido, seguindo os desenvolvimentos sociais por meio das tecnologias. Apesar de inúmeras dificuldades que foram se delineando no curso da história, muito se conseguiu percorrer e evoluir nos contextos educacionais. A discussão e criação de novas linhas de pensamento a partir da pesquisa permitiu que se desenvolvessem novas compreensões acerca do ato educativo. Nesse sentido, "A utilização multiforme dos computadores para o ensino está se propagando na escola, na casa, na formação profissional e contínua. Essa utilização carrega em si uma redefinição docente e de novos modos de acesso aos conhecimentos" (Levy, 2010, p. 26-27).

É inegável que a abertura da sala de aula formal ao uso de tecnologias vem evoluindo gradativamente, tomando corpo nas escolas e também de uma maneira ainda considerada tímida nos processos formativos docente. Pensamos que ainda na Universidade o futuro professor precisa ter contato com as mais diversificadas e variadas abordagens didáticas que utilizem as TDIC como base auxiliadora a sua atuação com os alunos no chão da sala de aula nas escolas. Sabemos que o incentivo ao contato com os saberes utilizando computadores nas escolas ocorreu a partir de diversas ações configuradas a partir de políticas públicas, porém houve um estagnação nesse sentido, configurado fortemente pela falta verbas destinadas a esse fim, pois sabemos que os equipamentos ficam obsoletos muito rápido quando pensamos nessas questões tecnológicas, precisando, assim, de investimento constante.

A segurança emocional, afetiva e intelectual são requisitos de qualquer profissional, seja no campo tecnológico ou não, se é que pode um campo hoje em dia estar desvencilhado das tecnologias. Dessa forma, o discente precisa de uma formação que embase suas decisões. É papel do professor estabelecer elos entre os saberes profissionais e as tecnologias, mas como sua formação pode não ter privilegiado essas questões, sente-se 
inseguro em estimular isso no aluno ou até mesmo construir com ele os saberes necessários para utilização das TDIC (Almeida Valente ,( 2011). O laboratório é um espaço dentro da escola que pode fomentar essa série de discussões sobre e com as tecnologias. Necessitando de abordagens pedagógicas bem conceituadas e construídas a partir da valorização dos saberes dos alunos, a aula precisa ser construída a partir da articulação de diversos saberes e práticas pedagógicas. Essas atitudes não podem ser as mesmas do ensino tradicional, e configuram-se a partir de diversos modelos e estruturas, seja na educação à distância, no ensino remoto, no ensino híbrido, ou até mesmo no ensino presencial que se faz uso das tecnologias.

Dentro da atual realidade da educação, impedir a construção de atividades nas ferramentas digitais representa um grande retrocesso. Há uma grande disponibilidade de softwares educativos que distribuem-se nas mais diversas disciplinas que compõem a grade curricular das escolas. Exemplos como as planilhas eletrônicas, internet entre outros, amparam um diálogo formativo entre professor e aluno, entre alunos, e entre essas pessoas e os saberes. Esse dividir das experiências com o outro representa um grande avanço sobre a aprendizagem dentro de contextos da cidadania. Esta prática precisa passar por um processo de amadurecimento que surge a partir de discussões entre as pessoas envolvidas. Então, não é só o professor, mas deve haver o envolvimento da gestão, dos alunos, objetivando o desenvolvimento desses novos saberes a partir de saberes já mobilizados previamente (Ausubel , (2008), RIBEIRO et al., (2008), Pontes (2010).

Dentro da educação temos diversas subáreas que foram se configurando e delineando dentro das tantas variáveis que são percebidas pelos estudiosos. Assim, a partir dos conceitos e recursos da informática, a educação vai construindo uma nova área denominada educação informatizada. Com fundamentos pautados inicialmente no uso do computador como meio para potencializar a aprendizagem, ultrapassando barreiras limitantes do ensino, atingindo seus objetivos quando reconhece as possibilidades sociais que emergem da comunidade na qual a escola está inserida. Ainda, dentro desse uso apontamos que a

Informática na Educação é um novo domínio da ciência que em seu próprio conceito traz embutida a idéia de pluralidade, de inter-relação e de intercâmbio crítico entre saberes e ideias desenvolvidas por diferentes pensadores. Por ser uma concepção que ainda está em fase de desenvolver seus argumentos, quanto mais nos valermos de teorias fundamentadas em visões de homem e de mundo coerentes, melhor será para observamos e analisarmos diferentes fatos, eventos e fenômenos, com o objetivo de estabelecer relações entre eles. (Almeida, 2000, p.19)

Assim, não há como se apropriar de termos, funções ou da própria informática sem estar preparado para articular com ideias da educação. Essa apropriação não acontece para uma perspectiva austera, dominante, verticalizada, devendo dialogar com seus alunos de forma horizontal, respeitando suas vivências, relações e saberes, construindo pontes para que o discente desenvolva novos saberes entre aquilo que já tem consolidado e os tremores que o professor move ao propor novos saberes. Tais preceitos buscam uma formação crítica, dialógica, consciente, apropriada e apropriadora de recursos informacionais, sejam eles em termos de hardware ou software. Como exemplo de tecnologia que estabelece uma relação com a educação, temos o computador, exercendo uma função de melhoria para os processos educacionais, pois constrói ou auxilia a construção de ferramentas que subsidiam o reconhecimento de limites didáticos, permitindo, assim, o desenvolvimento de ferramentas que embasem a transposição desses (Ribeiro et al., 2008).

O processo de globalização permitiu às diversas localidades e povos estabelecerem uma série de interações que suscitaram interrelações, exigindo, assim, diversas competências para lidar com os contextos produtivos que se apresentavam. Esse movimento vai demandar na educação uma formação mais qualificada e complexa do homem, objetivando proposições de solução para problemas que se estabeleciam no cotidiano. Assim, na educação usar o computador permite ao professor estimular essa construção dos conhecimentos dos alunos, apontando a uma maior humildade docente, permitindo o aluno enxergar o docente como um ser acessível, 
conversando com ele sobre suas dúvidas, questões e percepções. Nos dias atuais temos, nas escolas, uma maior intensificação do uso dessas ferramentas, fato esse que tem proporcionado grandes descobertas e sendo mote para novas pesquisas, apontando-se como elemento constituinte do estímulo tão necessário à aprendizagem discente.

\section{Dialogando sobre aprendizagem}

A abordagem construcionista nos permite uma diversidade de contextos sobre a aprendizagem. Assim, dentro do nosso foco, temos trabalhos que ressaltam a importância do uso do computador como ferramenta para refletir a educação e construir uma discussão sobre o seu uso como forma de potencializar as aprendizagens. Entre tantos, apontamos Almeida (2000), Papert (1994), Valente (2003) e Almeida; Valente (2011) fundamentamos nossas discussões sobre uma perspectiva construtivista em Piaget (1972).

A ideia principal do construtivismo que discutimos está alicerçada num processo de desenvolvimento de conhecimento sendo construído de forma crescente e progressiva, mas não desordenada, segue uma estruturação sobre a ação. Assim, não se trata de um mero depositar, pois "O conhecimento não é transmitido. Ele é construído progressivamente por meio de ações e coordenações de ações, que são interiorizadas e se transformam. A inteligência surge de um processo evolutivo nos quais muitos fatores devem ter tempo para encontrar seu equilíbrio." (Piaget 1972, p.14).

Disso, pensar o construcionismo já é caminhar para uma metodologia construtivista e a utilização das ferramentas tecnológicas digitais como computador, smartphones, tablets atuando instrumentalmente no sentido de subsidiar o desenvolvimento, mobilização, e articulação do conhecimento. Assim, dentro da base do que se concebe como escola, o aluno é o foco no qual pensamos a educação e o professor como um mediador para, a partir de diálogos, formar com esse outro concepções que desenvolvam a sociedade (Ameida,( 2000); ALMEIDA; VALENTE, (2011).

O sujeito que aprende, seja ele professor ou aluno, interage com as ferramentas tecnológicas digitais e, a partir disso, há um desencadeamento de ações pedagógicas que são capazes e vão interferir nas formas como cognição se dá, mobilizando saberes antigos, rearranjando com os novos, nessa articulação que permite o desenvolvimento de novas percepções e saberes. Há uma sequência cíclica sobre a forma como esse desenvolvimento se dá partindo da ação, descrição - execução - reflexão - depuração e retornando a uma ação que se configurará de uma nova forma, pois já foram articulados diversos saberes. Essa discussão de processos pode ser ilustrada como uma espiral (VALENTE, 2002). Os jogos de linguagem se inserem aqui, pois o sujeito que aprende precisa conceber uma linguagem que possa traduzir e descrever o problema para uma linguagem que o recurso tecnológico digital compreenda e, assim, construir uma sequência de passos em busca do resultado, que será adequado ao que lhe foi solicitado.

Disso, o discente precisa compreender bem o problema, suas variáveis, suas camadas, bem como necessita refletir como essa linguagem se relaciona à linguagem da tecnologia com a qual ele trabalha. Só nisso já temos toda uma articulação de saberes, reflexão, levantamento e teste de hipóteses para que atinja o resultado que se dedica nessa busca. Mas o resultado não representa uma finalização desse espiral, pois agora é o ponto de verificar se esse resultado foi condizente, se atende ao que se pretendia pedir ao computador, então verificar o que foi pedido, verificar se o que foi pedido condiz com o que se pretendia pedir. Nesse processo há como aponta Valente (1997) o desenvolvimento e esquematização do conhecimento, pois além de saberes antigos, o aluno investiga novos para mobilizar os que já tem. 
Assim, ainda em Valente (2002) temos uma justificativa para trabalhar com as TDIC, pois são capazes de apontar para subsídios didáticos para docentes e discentes dentro de contextos da colaboração entre eles, onde ambos ensinam e aprendem os seus saberes. Nesse contexto que vivenciamos hoje de pandemia não é raro perceber alunos ensinando professores trabalhar com determinadas plataformas e, assim, vão trocando saberes a partir das suas experiências e vivências. Os contextos imaginativos devem ser valorizados aqui, mas o professor precisa mediar no sentido de não deixar que as discussões percam seu sentido, pois a espiral proposta nesse processo precisa ser bem estruturada e configurada no sentido de agir, coletar resultados, promover a reflexão acerca deles buscando um amadurecimento e chegando a uma ação nova, pois precisa verificar os seus testes evidenciando a ciclicidade dessa espiral (Valente, (2002), Ribeiro, (2008).

Integrar a formação docente às concepções sobre as TDIC e capacitar para o seu uso, compreendendo e estabelecendo possíveis interlocuções permite ao professor a construção de uma gama de oportunidades sobre a segurança necessária para que medie os processos de desenvolvimento cognitivo e a articulação dos saberes com seus alunos.

\section{Conclusões}

As contribuições da didática, de forma integrada às TDIC em sua concepção e seu uso, ao currículo dos cursos de formação docente contribuem para uma nova ideia de currículo e para o desenvolvimento de uma nova prática pedagógica. Quando pensamos no desenvolvimento humano, não necessariamente pensando na educação na díade ensino-aprendizagem, percebemos como a qualificação dos professores leva a processos reflexivos sobre suas bases teóricas, promovendo uma criatividade ética. Tal pensamento só acontece se essa criatividade leva a processos que incentivam o outro a desenvolver suas potencialidades, maturando conceitos, vivências e identidades.

Baseado no construcionismo, a utilização das TDIC contribui fortemente para esse processo de criatividade ética, pois permite ao professor pensar em estratégias que melhoram o ensino, pois esse pensa em como mediar o contato dos alunos com as TDIC, os saberes de forma intra e interrelacional. Tal atitude, seguramente proporcionará ganhos significativos para educação, para a formação de cidadãos conscientes do seu papel no exercício da cidadania, minimizando obstáculos e estendendo os pontos limitantes da formação docente, pois sabemos que esses limites não serão extintos, mas pensando num círculo limitante dessa formação, podemos ampliar o raio desse círculo ao inserir nele novos saberes.

Esperamos enfim, que essas reflexões possam contribuir para uma racionalidade e dialogicidade em processos interacionais do professor, aluno e saber fazendo uso mais adequado das TDIC pela escola possibilitando melhores desempenho acadêmicos dos sujeitos envolvidos no processo educacional.

Essa investigação nos proporcionou a compreensão acerca de uma a maior necessidade de discutir e aprofundar em novas explorações, as estreitas relações que se podem estabelecer envolvendo o processo de formação docente ao uso das TDIC. O diálogo sobre os aportes teórico e prático podem trazer contribuições significativas e potenciais apontamentos para situações evidenciadas neste trabalho em relação às interações que ocorrem mediadas durante o fazer pedagógico se valendo de ferramentas com foco na mediação para o aprender.

Concluímos, assim, deixando espaço para trabalhos futuros, a referida pesquisa nos possibilitou a construção de novas percepções e concepções do uso das TDIC a partir de um panorama que permita ampliar os horizontes metodológicos para auxiliar docentes em suas relações nos contextos da sala de aula com os discentes, bem como no planejamento dessas ações. 


\section{Referências}

ALMEIDA, M. E. B. (2000a). Informática na Educação. In: Prolnfo: Informática e formação de professores. Brasília: Ministério da Educação/SEED, vol(1), p.19-47.

ALMEIDA, M. E. B. (2000b). A formação do professor para uso pedagógico do computador. In: Prolnfo: Informática e formação de professores. Brasília: Ministério da Educação/Seed, vol(2), p.107-119.

ALMEIDA, F. J., \& FONSECA JR., F. M. (2000). O que pode ligar a informática às questões da escola? In: Prolnfo: Projetos e Ambientes Inovadores. Brasília: Ministério da Educação/Seed, vol(2), p.107-119.

ALMEIDA, M. E. B., \& VALENTE, J. A. (2011). Tecnologias e currículo: trajetórias convergentes ou divergentes? São Paulo: Paulus.

AUSUBEL, D. P., NOVAK, J. D., \& HANESIAN, H. (1968). Educational psychology: a cognitive view. New York. USA: Ed. Holt, Rinehart and Winston.

FREIRE, P. (1997). Pedagogia da autonomia: os saberes necessários à prática educativa. São Paulo: Paz e Terra.

FREIRE, P. (1997). Professora sim, tia não. Cartas a quem ousa ensinar. São Paulo: Olho d'Água.

GAUTHIER, C., BISSONNETTE, S., \& RICHARD, M. (2014). Ensino explícito e desempenho dos alunos - a gestão dos aprendizados. Petrópolis: Vozes.

IMBERNON, F. (2011). Formação docente e profissional: formar- se para a mudança e a incerteza. Tradução Silvana Cobucci Leite. 9 ed. São Paulo: Cortez.

LÉVY, P. (2010). Cibercultura. São Paulo: Editora 34.

LIBÂNEO, J. C. (2011) Educação, pedagogia e didática. O campo investigativo da pedagogia e da didática no Brasil: esboço histórico e buscas de identidade epistemológica e profissional. In: PIMENTA, Selma Garrido (org.). Didática e formação de professores: percursos e perspectivas no Brasil e em Portugal. São Paulo: Cortez.

LIBÂNEO, J. C. (2014) O Campo Teórico e Profissional da Didática Hoje: entre Ítaca e o canto das sereias. In: FRANCO, Maria Amélia Santoro; PIMENTA, Selma Garrido. Didática: embates contemporâneos. 3. ed. São Paulo: Edições Loyola, p. 43-73.

LIMA, M. S. L. (2013). Formação de professores para a educação superior: questões pedagógicas do estágio de docência, UECE.

LIMA, L. (2014) Integração das tecnologias e currículo: a aprendizagem significativa dos licenciandos de ciências na apropriação e articulação entre saberes científicos, pedagógicos e das TDIC. 2014. 154f. Tese (Doutorado em Educação) - Programa de Pós-Graduação em Educação Brasileira, Universidade Federal do Ceará. Fortaleza.

LIMA, M. S. L. (2014). Tendências investigativas contemporâneas no campo da didática: aspectos teóricos e metodológicos. In: ENCONTRO DE PESQUISA EDUCACIONAL NORTE E NORDESTE - EPENN, 22., 2014. Natal - RN, Anais... Natal - RN: [s.n.].

NETO, H. B., \& JUNQUEIRA, E. (2009) O que é inclusão digital?: um novo referencial teórico. Linhas Críticas, Brasília, vol(15), p. 345-362. 
OKADA, A. L. P(2013). Recursos Educacionais Abertos \& Redes Sociais. São Luís: UEMA. Disponível em: <https://oro.open.ac.uk/39236/1/OER-completo-final-05-07.pdf>. Acesso em: 16 maio 2019.

PAPERT, S. A. (1994). Máquina das Crianças - Repensando a Escola na Era da Informática. Trad. Sandra Costa. Porto Alegre: Artes Médicas.

PIAGET, J. A. (1972). Epistemologia Genética, Editora Vozes - Petrópolis, RJ.

PIAGET, J. A. (1998). Sobre a Pedagogia. Textos inéditos. São Paulo: Casa do Psicólogo.

PIMENTA, S.G. (2012). Saberes pedagógicos e a atividade docente. 3. Ed. São Paulo: Cortez.

PINHEIRO, A. C. M.; (2016). Concepção e desenvolvimento de uma formação continuada de professores de matemática baseada na sequência FEDATHI. 2016. 156f. Tese (Doutorado em Educação) - Universidade Federal do Ceará, Faculdade de Educação, Programa de Pós-graduação em Educação Brasileira, Fortaleza.

PONTES, H. U. N. (2010). Uso de software educativo no ensino médio para facilitar a aprendizagem significativa e cooperativa de funções. Dissertação de Mestrado Profissional. Programa de Pós-graduação em Ensino de Ciências e Matemática. UFC-CE.

RIBEIRO, J. W., VALENTE, J. A., FREITAS, D. B., MARTINS, D. G., \& SANTOS, M. J. C. (2008). Integração de Atividades de Educação em Ciências Utilizando TIC: Uma Experiência na Formação Continuada de Educadores do Ensino Médio. I Seminário Web Currículo PUCSP. Ed CD ROM. pp. 10. SP

RIBEIRO, J. W. (2012) Ensino de Ciências: sociedade, TIC e laboratório de experimentação. In: Litto, F.; Formiga, M. (Org.). Educação a Distância: o Estado da Arte, vol(2), 2. ed. São Paulo: Pearson Education do Brasil, p. 443.

SACRISTÁN, J. G. (1999). O que move a ação educativa? A racionalidade possível na pós-modernidade e a relação teoria-prática. In: SACRISTÁN, J. Gimeno. Poderes instáveis em Educação. Porto Alegre: Artes Médicas Sul, p. 17-69.

TARDIF, M. (2008) Saberes docentes e formação profissional. Petrópolis: Vozes.

THERRIEN, J. (2006). Os saberes da racionalidade pedagógica na sociedade contemporânea. Revista Educativa, v. .9, n. 1, p. 67-81.

VALENTE, J. A. (1997). O uso inteligente do computador na Educação, Pátio - Revista Pedagógica, Porto Alegre: Artes Médicas Sul, ano 1, n.1, p.19-21, maio/jul. 1997.

VALENTE, J. A. (2002). A espiral da aprendizagem e as tecnologias da informação e comunicação: repensando conceitos. In: JOLY, M. C. (Org.). A tecnologia do ensino: implicações para a aprendizagem. ed. 2002. São Paulo: Casa do Psicólogo.

VALENTE, J. A. (2003). Formação de Educadores para o Uso da Informática na Escola. Campinas, SP: Ed. UNICAMP/NIED.

YOUNG, R. S. (2014). Inserção das interfaces digitais interativas (IDI) no ensino presencial superior: práticas educativas e formação docente no curso de pedagogia da UERN, 2014. 189f. Tese (doutorado) Universidade Federal do Ceará, Faculdade de Educação, Programa de Pós-graduação em Educação Brasileira, Fortaleza.

Esta obra está bajo una Licencia Creative Commons Attribución-NoCommercial 4.0 International

$(\mathrm{CC}) \mathbf{B Y}-\mathrm{NC}$ 